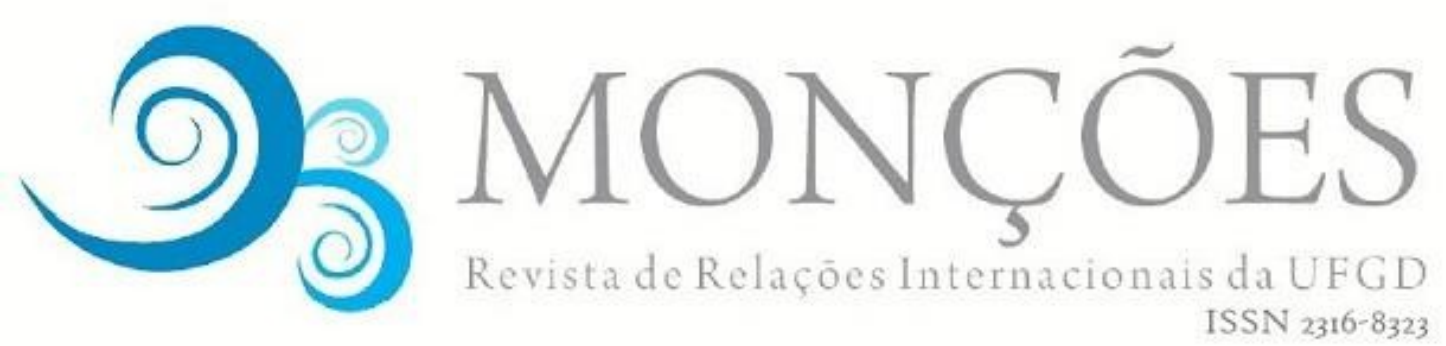

\title{
ATORES INTERNACIONAIS E PODER CIBERNÉTICO: O PAPEL DAS TRANSNACIONAIS DE TECNOLOGIA NA ERA DIGITAL
}

MARCELO PASSINI MARIANO

Professor Doutor no curso de Relações Internacionais da UNESP, campus Franca, e no Programa de Pós-Graduação em Relações Internacionais San Tiago Dantas

(UNESP - UNICAMP - PUC/SP)

Pesquisador do Laboratório de Novas Tecnologias de Pesquisa em Relações Internacionais

(LANTRI/UNESP) e da Rede de Pesquisa em Política Externa e Regionalismo (REPRI)

JAQUELINE TREVISAN PIGATTO (bolsista FAPESP)

Mestranda no Programa de Pós-Graduação em Relações Internacionais San Tiago Dantas (UNESP - UNICAMP - PUC/SP)

Pesquisadora do Laboratório de Novas Tecnologias de Pesquisa em Relações Internacionais (LANTRI/UNESP) e da Rede de Pesquisa em Política Externa e

Regionalismo (REPRI)

\section{RAFAEL AUGUSTO RIBEIRO DE ALMEIDA}

(bolsista FAPEMIG)

Mestrando no Programa de Pós-Graduação em Relações Internacionais da Universidade

Federal de Uberlândia (UFU)

Pesquisador do Laboratório de Novas Tecnologias de Pesquisa em Relações Internacionais

(LANTRI/UNESP) e da Rede de Pesquisa em Política Externa e Regionalismo (REPRI)

RESUMO: Este artigo analisa as relações de poder em um mundo onde as novas tecnologias digitais modificam as capacidades dos atores internacionais, tendo consequências diretas sobre os Estados nacionais e as instituições internacionais. As relações internacionais são abordadas a partir da discussão sobre a expansão do ciberespaço, procurando compreender como as sociedades reagem às mudanças no padrão de interação social e como os recursos de poder cibernético são utilizados pelas transnacionais das tecnologias de informação e comunicação. Destaca-se o papel crescente dos algoritmos na vida social e também como instrumento de poder, a fim de refletir sobre as transformações nos processos de socialização internacional e a crescente dificuldade para estabelecer consensos e convergir expectativas dos diferentes atores em torno de objetivos coletivos. Por fim, a maior pluralidade de atores com capacidades de influência no sistema internacional e a disputa para ter acesso, concentrar e manter recursos de poder cibernéticos são apresentados como um dos principais motivos das mudanças que vêm ocorrendo no cenário atual.

PALAVRAS-CHAVE: ciberespaço; instituições; poder. 


\title{
INTERNATIONAL ACTORS AND CYBER POWER: THE ROLE OF TECHNOLOGY TRANSNATIONAL ACTORS IN THE DIGITAL AGE
}

\begin{abstract}
This article analyses the power relations in a world where new digital technologies change the capacity of international actors, having direct consequences on the national states and the international institutions. The international relations are approached from a discussion about the cyberspace expansion, hoping to understand how the societies react towards the changes on the social interaction pattern and how the resources of cybernetic power are utilized by transnational corporations of information and communication technologies. It is outstanding the increasing role of algorithms on social life and also as an instrument of power, in order to reflect on the transformations of international socialization processes and the increasing difficulty to establish consensus and converge expectations from different actors around collective goals. In conclusion, the biggest plurality of actors with influence capacity at the international system and the dispute for having access, to concentrate and to maintain resources of cybernetic power, are presented as one of the main reasons for the changes that have been occurring at the current scenario.
\end{abstract}

KEYWORDS: cyberspace; institutions; power.

\section{Introdução}

A partir de 2002 a quantidade de linhas de telefonia fixa foi superada pela linhas de celulares ${ }^{1}$ e, em $2016,45,7 \%$ da população mundial ${ }^{2}$ passou a utilizar a Internet $^{3}$. A grande maioria destes usuários se relaciona com alguma transnacional de tecnologia via telefonia móvel seja fazendo uma pesquisa no Google, assistindo um vídeo do YouTube, acessando o GMail ou o Outlook, interagindo em redes sociais, como Facebook e Twitter, ou trocando mensagens no Whatsapp. Grande parte dos demais serviços e sites que são utilizados pelos usuários utilizam a infraestrutura de nuvem fornecida pela Amazon ou pelo Google.

Empresas como Google e Facebook utilizam esta ampla penetração no cotidiano das pessoas para ganhos comerciais através de propaganda, mas também acabam por deter um grande conhecimento do comportamento social e preferências

\footnotetext{
${ }^{1}$ Fixed telephone subscriptions. World Bank database. Disponível em: $<$ https://data.worldbank.org/indicator/IT.MLT.MAIN>. Acesso em: 11 jun. 2018. A evolução do número de linhas de telefone fixo e celular no mundo. Nexo Jornal, 02 maio 2018. Disponível em:<https://goo.gl/hBWHZc>. Acesso em: 15 maio 2018.

2 Individuals using the Internet (\% of population). World Bank database. Disponível em: $<$ https://data.worldbank.org/indicator/IT.NET.USER.ZS >. Acesso em 11 jun. 2018. . Ver também Global Digital Report 2018. Diponível em: <https://digitalreport.wearesocial.com>. ACesso em: 06 jun. 2018.

${ }^{3}$ Utilizamos a grafia de Internet com inicial maiúscula para diferenciar a rede mundial de computadores de outras redes possíveis (internets) que podem ser abertas ou fechadas.
} 
dos indivíduos ${ }^{4}$. Em 2017, por exemplo, o Facebook atingiu a marca de 2 bilhões de usuários ativos, que estão sujeitos diariamente ao funcionamento de seus algoritmos $^{5}$. Assim, sem desconsiderar movimentos que buscam uma interação virtual descentralizada e que preserve a privacidade individual, observa-se uma enorme concentração dos fluxos de comunicação digital em poucas e grandes empresas transnacionais de tecnologia.

Assim, o principal objetivo deste artigo é analisar os aspectos que definem os recursos e as relações de poder no espaço cibernético, observando o crescente papel das grandes corporações privadas de tecnologia. Trazer um panorama desses novos tempos em que o ciberespaço avança sobre as relações internacionais, tendo consequências importantes para os Estados e os demais atores, também pode fornecer uma melhor compreensão dos desafios que as instituições internacionais enfrentam neste início de século XXI.

A partir da literatura que trata das questões relacionadas ao ciberespaço nas relações internacionais, procura-se chamar a atenção para seis recursos de poder cibernético que auxiliam a compreensão aspectos fundamentais que permeiam a interação na sociedade em rede. Argumentamos que não é possível compreender a grande crise de expectativas vivida nos dias atuais, tanto no nível doméstico quanto no internacional, ocasionada em grande medida pelo descompasso entre 0 desenvolvimento tecnológico acelerado e a lentidão das instituições em se adequarem a esta nova realidade, sem refletir sobre os recursos de poder cibernéticos disponíveis e como estes são utilizados pelos atores preponderantes no atual contexto histórico.

Deste modo, será analisado os significados e definições conferidos ao espaço e ao poder cibernético, para em seguida identificar e detalhar os principais recursos de poder da era digital: conhecimento sobre as tecnologias digitais, dados digitais, infraestrutura informacional, capacidade computacional, bases de usuários

\footnotetext{
${ }^{4}$ Is your data safe on Facebook? Not really. CNN Tech, 20 mar 2018. Disponível em: $<$ http://money.cnn.com/2018/03/19/technology/business/facebook-data-breach/index.html>. Acesso em 14 maio 2018.

${ }^{5}$ Facebook Stats. Newsroom.fb, jun 2017. Disponível em: <https://newsroom.fb.com/company-info/>. Acesso em 2 ago 2017.
} 
e, por fim, os algoritmos, considerado como o recurso de maior relevância para compreender melhor o papel das das transnacionais de tecnologia na atualidade.

\section{O Espaço Cibernético nas Relações Internacionais}

A atividade da pesquisa científica nos ensina que a grande maioria dos objetos analisados não apresentam uma definição única e geral que é aceita universalmente no meio acadêmico. O espaço cibernético ou ciberespaço é um bom exemplo disso, pois é definido de inúmeras e distintas maneiras. Em grande medida, esta pluralidade de caracterizações pode ser justificada pelos diferentes aspectos que cada trabalho busca destacar.

De maneira geral, podemos caracterizar o ciberespaço como um conjunto de infraestrutura e equipamentos físicos, chamados hardware, aliado aos programas, sistemas e plataformas que podemos acessar pelos computadores, smartphones, entre outros aparelhos, os softwares. Autores como Daniel Ventre (2011), destacam ainda a importância dos seres humanos que manipulam essa arena (peopleware). Uma das definições mais aceitas para o ciberespaço é entendê-lo como uma rede global, gerada, acessada e sustentada por dispositivos interconectados. $O$ ciberespaço se refere a um espaço conceitual dentro das tecnologias de informação e comunicação (DODGE; KITCHIN, 2001). Há também, definições que destacam algum aspecto técnico do ciberespaço, como a trazida por Daniel Kuehl (2009, p.31), em que "what makes cyberspace neither aerospace nor outer space is the use of the electromagnetic spectrum as the means of 'movement' within the domain".

Uma característica importante do espaço cibernético é a maior inserção e o empoderamento de novos atores, devido ao gradativo barateamento dos meios de acesso ao ciberespaço, especialmente nos Estados Unidos e na Europa (CHOUCRI, 2014). Tais atores, que podem ser facilmente identificados na Internet ou atuar de maneira anônima, podem interferir nos níveis de assimetria de poder existentes.

É o caso de atores de menor poder relativo, como cibercriminosos que invadem sistemas computacionais de indivíduos, empresas e órgãos estatais, ou 
como o surgimento do Wikileaks, organização responsável por uma plataforma de publicação na Internet de documentos sigilosos de grandes empresas e Estados, na tentativa de trazer maior transparência de informações ao público.

Nazli Choucri (2014) também destaca a crescente importância de instituições destinadas ao ciberespaço, em sua maioria não estatais, criadas para a gestão das interações cibernéticas, como é o caso da Corporação da Internet para Atribuição de Nomes e Números (ICANN) e da Internet Engineering Task Force (IETF), que, entre outras atribuições, regulam os protocolos e a infraestrutura da Internet.

Há também autores, como Canabarro (2014), que apontam a importância do papel exercido pelos Estados Unidos na criação de órgãos como a ICANN e o IETF. Apesar de, em certa medida, os EUA projetarem seus interesses no espaço cibernético através dessas instituições, hoje se vê que o país vem perdendo parte de sua influência, especialmente sobre a ICANN e após o caso Snowden. No caso da ICANN, desde 2016 a supervisão já não pertence mais aos Estados Unidos. A partir de então esta instituição tem buscado reforçar seu caráter multissetorial, ou seja, sua composição por membros dos setores governamentais, privados, acadêmicos, comunidade técnica e sociedade civil. Como a transição da ICANN ainda é muito recente, é preciso mais tempo para ver como essa nova configuração funciona no sistema internacional da governança da rede.

Além disso, o lobby das empresas dificulta a regulamentação de vários pontos nos Estados Unidos, em grande parte devido à própria estrutura governamental do país que permite esse tipo de prática. Ao contrário disso vemos na Europa a entrada em vigor da Regulamentação Geral de Proteção de Dados $(\text { GDPR })^{6}$.

Joseph Nye (2011) também expõe sobre não haver uma governança global única que se encarregue do espaço cibernético, mas diversas instituições autônomas. Vale ressaltar que muitas delas possuem fortes laços com os Estados

\footnotetext{
${ }^{6}$ Reforma de 2018 das regras de proteção de dados da UE. Comissão Europeia. Disponível em: $<$ https://ec.europa.eu/commission/priorities/justice-and-fundamental-rights/data-protection/2018reform-eu-data-protection-rules pt>. Acesso em 12 maio 2018.
}

203 
Unidos, país onde a Internet se originou a partir das pesquisas realizadas nos anos 1960 para criação da ARPANET pela então Advanced Research Projects Agency $(\mathrm{ARPA})^{7}$. Essa origem e o posterior desenvolvimento e a expansão da Internet a partir do núcleo norte-americano gerou, por exemplo, reações da União Internacional de Telecomunicações (UIT) no sentido de questionar a legitimidade desses "novos espaços" e procurar inserir uma maior atuação por parte dos Estados, frente aos setores não estatais que dominam grande parte dessas tecnologias. No caso da governança da Internet, vemos diversas perspectivas, especialmente por instalar-se em um âmbito sem fronteiras, que tensiona a configuração westphaliana presente no sistema internacional.

Nye (2011) chega a afirmar que a Internet está proporcionando a todo tempo consequências nas esferas pública, privada e até mesmo individual, argumentando que os Estados poderão se tornar menos fundamentais na vida das pessoas por causa da Internet e dos novos padrões de comunidade e governança. Acontecimentos como a manipulação de dados do Facebook feito pela empresa de consultoria Cambridge Analytica, em 2016, para beneficiar a campanha de Donald Trump colocam em dúvida a ideia de Nye (2011), pois as dificuldades de regulação, seja estatal ou via algum organismo internacional, facilitou que tal prática ocorresse ${ }^{8}$. Neste sentido, Rafael Ávila e Marta Pinheiro (2014) indicam que há uma relação de interdependência entre as entidades estatais e não-estatais para com o uso da rede mundial de telecomunicações, estando o Estado em uma posição de constante pressão destas tecnologias de informação e comunicação.

É possível, inclusive, fazer um paralelo com o recente cenário de disseminação das criptomoedas, como o Bitcoin, e como as instituições financeiras e Estados se posicionam em relação a estas no sentido de regular ou tentar restringir sua difusão. Mesmo no campo da segurança cibernética, como coloca Choucri (2012), a ausência de uma governança e a dificuldade de controle ficou evidente na

\footnotetext{
${ }^{7}$ Vinculada ao governo do EUA, a ARPA foi criada por militares e pesquisadores norte-americanos com o objetivo principal que estimular o desenvolvimento tecnológico dos EUA.

${ }^{8}$ Como os dados de milhões de usuários do Facebook foram usados na campanha de Trump. BBC Brasil, 9 abr 2018. Disponível em: <http://www.bbc.com/portuguese/geral-43705839>. Acesso em 12 maio 2018.
} 
medida em que os ataques aumentaram ao longo do tempo, o que fez com que alguns governos investissem nacionalmente em centros de defesa cibernética.

Ataques cibernéticos podem coletar indevidamente dados de individuais, organizações ou governos. Além disso, podem atingir infraestruturas industriais, como o caso do vírus Stuxnet ${ }^{9}$ que afetou operações nucleares iranianas em 2009. Esses ataques se transformaram em armas políticas, inclusive com apoio de Estados (LEMOS, 2017). Verifica-se que a percepção de ameaça cresce em razão da ampliação do espaço cibernético, mas também devido a maior importância atribuída aos temas de segurança na agenda internacional desde 2001, quando dos atentados terroristas aos Estados Unidos.

Lucas Portela (2016) expõe que na área das Relações Internacionais, as publicações que tratam do ciberespaço começaram a aumentar a partir de 2008, época em que crescem as preocupações com defesa cibernética no leste europeu. Ademais, é a partir deste período que ocorre um maior desenvolvimento das tecnologias envolvidas na chamada computação em nuvem, tendo como importante exemplo o início das operações da Amazon Web Services (AWS) em 2006, ofertando serviços de infraestrutura de tecnologia da informação através da Internet.

A diminuição dos custos de poder computacional propiciada pelos serviços de computação em nuvem foi um grande estímulo para a aceleração da expansão do espaço cibernético: os celulares lideram o meio pelo qual se dá a conectividade nos últimos anos, junto com o aumento de indivíduos usando a Internet ${ }^{10}$. Nesse sentido, o crescimento de casos de ataques cibernéticos desde então fez com que a segurança cibernética fosse o principal tema tratado pelas Relações Internacionais no que concerne ao espaço cibernético.

\footnotetext{
${ }^{9} \mathrm{O}$ vírus Stuxnet foi programado especialmente para atacar sistemas industriais de usinas nucleares, sendo utilizado em 2009 para danificar centrífugas do programa nuclear iraniano. Devido a sua alta complexidade, especula-se que seu desenvolvimento tenha tido investimentos de governos e um grande número de especialistas, mas nada foi provado.

${ }^{10}$ Indicadores do aumento de uso de tecnologias de informação e comunicação (TICs). União Internacional de Telecomunicações, disponível em: <https://www.itu.int/en/ITUD/Statistics/Pages/stat/default.aspx>.
} 
Além do vírus Stuxnet, são geralmente lembrados casos como os ocorridos no início de 2012 pelo grupo de hackers Anonymous, em diversos sites de empresas e governos em resposta ao posicionamento do governo dos Estados Unidos em relação ao direito de compartilhamento de arquivos digitais, tendo o site do FBI como um dos principais alvos; ou o ataque do vírus Wannacry ocorrido em 2017, que infectou diversos computadores no mundo para criptografar dados dos usuários a fim de pedir "resgate" (descriptografia) que deveria ser pago em bitcoins.

Cabe ressaltar que empresas como a Microsoft e a Kaspersky Lab chamam a atenção para o papel do governo norte-americano, via Agência Nacional de Segurança (NSA), na propagação deste do Wannacry, pois afirmam que elementos deste vírus foram conseguidos através de uma falha no sistema da NSA que armazena informações sobre vulnerabilidade de programas e sistemas. Assim, o Wannacry também evidencia o poder cibernético que determinado ator possui ao ter acesso a um grande banco de dados com informações sensíveis. Além disso, acaba por dar visibilidade ao amplo acesso de informações que estão ao alcance do governo norte-americano ${ }^{11}$.

\section{O poder cibernético}

O debate sobre as relações de poder nas Relações Internacionais não é recente e ocorre mesmo antes da institucionalização da área em meados do século $X X$. Importantes trabalhos acadêmicos procuram analisar o poder nas relações internacionais e suas características no século XXI (BARNETT e DUVALL, 2005; BERENSKOETTER e WILLIAMS, 2007; FINNEMORE e GOLDSTEIN, 2013; GUZZINI, 2013; BALDWIN, 2016). Neste artigo, optamos por ter como ponto de partida para nossas reflexões os trabalhos de Joseph Nye (2011).

Nye (2011, n.p) destaca a importância de se levar em consideração a atividade humana em determinado contexto histórico para se compreender mais

\footnotetext{
${ }^{11}$ É curioso que meses antes do ataque a Microsoft já havia liberado uma atualização que corrigiu a vulnerabilidade explorada pelo Wannacry, mas poucos máquinas haviam sido atualizadas. Por que a Microsoft culpa governos pelo ciberataque que já afetou mais de 200 mil pessoas. BBC Brasil. 15 mai 2017. Acesso em: 17 maio 2018.
} 
adequadamente as dimensões do poder em determinada época: "Any attempt to develop a single index of power is doomed to fail because power depends upon human relationships that vary in different contexts".

O autor contextualiza o século XXI como tendo o poder distribuído através de três fontes: poder militar, caracterizado em linhas gerais como unipolar; poder econômico, caracterizado como multipolar; e relações transnacionais, foco deste texto, caracterizado por ações que transcendem o controle dos Estados e incluem uma diversidade de atores não-estatais. Seu diagnóstico aponta também duas mudanças em torno do poder: a primeira é a transição de poder entre os Estados, especialmente a ascensão da Ásia, com destaque para China e Índia; a segunda é a intensificação da difusão de poder dos Estados em direção a atores não-estatais.

Nye (2011) também destaca dois aspectos sobre o poder: o seu caráter relacional e a importância dos recursos de poder. Destacar o caráter relacional do poder significa indicar a importância da percepção do outro sobre as capacidades do ator que busca condicionar o comportamento dos demais. Isaac Redd (2014, p.488), esclarece que o poder relacional diz respeito

a uma estrutura de relações ou vínculos entre atores (...) [que] determina a capacidade de certos atores de controlar ou limitar as ações dos demais, de concretizar suas vontades sobre e contra as vontades dos outros e, de maneira geral, de dirigir a vida social, frequentemente em seu favor.

Nye (2011) destaca três faces do caráter relacional do poder. A primeira face do poder relacional, chamada de commanding change, é a capacidade de comandar mudanças nas preferências iniciais em última instância via coerção. Segundo Nye (2011, n.p) "The important point is that someone has the capacity to make others act against their initial preferences and strategies, and both sides feel that power". Assim, esta face do poder se relaciona, em grande medida, a aspectos tangíveis e palpáveis como o uso da violência, pagamentos, sanções e incentivos econômicos e tecnológicos que objetivam adequar as preferências iniciais do ator. Este ator tem consciência e percebe claramente o poder exercido pelo ator com o qual está interagindo. 
Por suas características, esta face do poder nos remete a uma interação interestatal ou uma interação entre um ator estatal e um ator transnacional com a participação ou não de alguma instituição internacional, ou seja, o Estado teria uma centralidade nesta face do poder. Alguns casos, como a disputa internacional entre os padrões de TV Digital (relações interestatais) ${ }^{12}$; a atuação da Google na China (relações entre Estado e transnacional) ${ }^{13}$; e a contenda entre Google e União Europeia (relações entre uma instituição internacional e uma transnacional) ${ }^{14}$, realçam esta centralidade e apontam para a tentativa estatal de mudar a preferência e estratégia inicial de determinado ator através do oferecimento de benefícios ou constrangimentos. Nos três casos citados isso pode ser visto, respectivamente, via incentivos econômicos e tecnológicos para a adoção; via restrições de atuação no país; e via a uma pressão judicial. É interessante notar, como os casos que envolvem a Google evidenciam, a dificuldade que importantes atores internacionais têm para moldar as preferências das grandes transnacionais de tecnologia.

Porém, uma questão que está em aberto é se esta face do poder também pode ter um ator não-estatal como central, pois seu caráter de coerção não se restringe ao monopólio da violência, mas sim envolve também outros tipos de coerções, como apontado acima, que devem ser claramente percebidos e sentidos pelos atores envolvidos na interação.

\footnotetext{
${ }^{12}$ Especialmente na primeira década dos anos 2000, houve uma disputa entre quatro padrões de TV digital com os Estados oferecendo apoio e incentivos para a adoção de seu respectivo padrão: DVB (padrão europeu); ISDB-TB (padrão nipo-brasileiro); ATSC (padrão norte-americano); DTMB (padrão chinês). É interessante observar que a América do Sul aderiu, em grande parte ao padrão nipobrasileiro e que o padrão europeu alcançou a maioria dos países do mundo. Para mais detalhes consultar: Digital Broadcast Standards Map, Wikipedia, 10/jan/2018. Disponível em <https://goo.gl/u8aDVP> . Acesso em 15 mar. 2018; Comparison of 3 DTTB systems. DiBEG, sem data. Disponível em <https://archive.is/OUM2W>. Acesso em 15 mar. 2018; MACHADO FILHO, Francisco. Padrão de TV Digital brasileiro Conquista a América e parte para o Mundo. Fórum, Convergência Midiática, 14 fev. 2011.

${ }^{13} \mathrm{Em}$ abril de 2010, a Google encerrou suas operações na China, pois não concordava com as instruções do governo chinês em relação às restrições a Internet no país. Nos últimos anos essa transnacional tem tentado retornar ao mercado que em 2015 alcançou a marca de 690 milhões de pessoas com acesso a Internet. Para mais detalhes consultar: Google ainda negocia volta à China. Tele Síntese, 13 mar. 2017.

${ }^{14} \mathrm{Em}$ abril de 2015, a Comissão Europeia abriu uma investigação contra a Google sob a alegação de fragilizar a concorrência no serviço de comparação de preços devido ao favorecimento de "seus próprios serviços sem que os usuários tenham consciência do viés". Em junho de 2017, a Google foi condenada a pagar uma multa de 2,4 bilhões de euros. Para mais detalhes consultar: ABELLÁN, Lucia. União Europeia multa Google por monopólio em quase 9 bilhões de reais. El País, Economia, 27 jun. 2017.
} 
Normalmente, tanto as startups ${ }^{15}$, em especial as voltadas à área tecnológica (por exemplo, as fintechs ${ }^{16}$ ), como as grandes transnacionais de tecnologia (Amazon, Facebook e Google), têm como uma de suas características principais trazer negócios tradicionais para o espaço cibernético. Este movimento gera inúmeros impactos na organização da sociedade e na sua capacidade de adaptação, além de aumentar as pressões para ajustes de legislações que, muitas vezes, não são realizadas na mesma velocidade das transformações impulsionadas por estas empresas. Este descompasso sempre esteve presente na história da humanidade quando novas formas de interação e produção surgiram, basta ver os impactos das Revoluções Industriais. Mas o descompasso gerado pelas inovações promovidas pelas transnacionais de tecnologia, por exemplo, em Inteligência Artificial e Big Data, ocorre em um curto espaço de tempo e em escala global. Isso torna mais difícil tanto a compreensão destas transformações como também a articulação dos atores afetados. Por atuarem em um campo pouco conhecido e regulamentado, estas transnacionais podem também desenvolver importantes capacidades para comandar mudanças, alterando as preferências dos atores, ainda que muitas delas tenham se desenvolvido a partir de financiamentos estatais.

Por exemplo, a Amazon, através principalmente do Amazon Marketplace e do Amazon Web Services, gerou uma expansão do varejo online fornecendo a empresários uma plataforma de ecommerce e uma infraestrutura computacional em nuvem escalável de baixo custo e amplo alcance, sendo líder mundial em ambas as frentes $^{17}$. Isso não necessariamente fornece uma capacidade de alterar coercitivamente as preferências de outros atores, porém esta transnacional se direciona para a área de empréstimos para pequenas empresas que desde 2008 tem dificuldades de conseguir financiamentos por meios tradicionais. Segundo Rohit Arora, CEO da Biz2Credit, "Since Amazon Lending launched in 2011, it has

\footnotetext{
${ }^{15}$ Segundo Rafael Tortaro "As Startups são empresas jovens ou em fase de desenvolvimento, inovadoras e criativas, com a capacidade de estabelecer um modelo de negócio que seja repetível, com um grande potencial de escalabilidade, e trabalham em condições de incerteza". TORTARO, Rafael. Afinal, o que é uma Startup?, Sebrae (PR), 19 de novembro de 2013. Disponível em: $<$ https://archive.is/2MwhO>. Acesso em 15 de março de 2018.

${ }^{16}$ Fintech é um tipo de startup que atua no setor financeiro inserindo novas tecnologias para facilitar o acesso a serviços financeiros através da automatização e virtualização das atividades deste setor.

${ }^{17}$ VICENTIN, Tissiane. Se cuida, Amazon! Alibaba dobra lucro e quase alcança a 'rival' do Ocidente. TecMundo, Mercado, 18 de agosto de 2017; AWS mantém liderança em cloud, mas Microsoft e Google têm maior crescimento. ComputerWorld, 06 de fevereiro de 2018.
} 
surpassed $\$ 3$ billion in loans to small businesses. Further, more than 50 percent of the companies eventually take a second loan from Amazon"18.

Karen Mills, responsável pela área de pequenos negócios no governo de Barack Obama, também afirma que

\begin{abstract}
If you think about what Amazon already knows about its merchants, and then you think what Google knows about everybody who is buying and selling through its platform, one can imagine a world where they have much more information about both on the credit side but also on the small business itself ${ }^{19}$.
\end{abstract}

Este movimento de grandes transnacionais em direção à área financeira ainda não apresenta regulamentação e pode fornecer a estas empresas capacidade de poder coercitivo. Até um relatório do Fórum Econômico Mundial já apontou esta ameaça $^{20}$.

A primeira face do poder está voltada para a compreensão de decisões intencionais dos atores individuais tendo como pano de fundo ao menos a possibilidade de coerção e está no campo do que Nye (2011) denomina de command power. As outras duas faces do poder, como veremos a seguir, se relacionam com a formação de preferências iniciais e decisões não necessariamente intencionais sem a presença da possibilidade de coerção. Estas duas faces do poder estão no campo do que Nye (2011) denomina de co-optive power. Tanto a segunda como a terceira face do poder compõem um poder estrutural que limita e molda as escolhas e preferências das decisões intencionais da primeira face do poder. Deste modo, para se compreender as relações de poder é importante avaliar as escolhas individuais e as forças estruturais.

A segunda face do poder, denominada de controlling agendas é a capacidade de moldar as preferências iniciais através do fomento de expectativas do que é legítimo e viável. Nesta face do poder se destaca a capacidade de manter no

\footnotetext{
${ }^{18}$ ARORA, Rohit. Another industry Amazon plans to crush is small-business lending: Op-Ed. CNBC, 16/jun/2017. Disponível em: <goo.gl/qJnKci>. Acesso em: 19 mar 2018.

${ }^{19}$ BROWNE, Ryan. Google and Amazon are ready to disrupt small business lending, former Obama advisor says. CNBC, 13 de outubro de 2017.

${ }_{20}$ WORLD ECONOMIC FORUM. Beyond Fintech: A Pragmatic Assessment Of Disruptive Potential In Financial Services, August, 2017. Disponível em: <https://goo.gl/PpCQa8> Acesso em: 15 de março de 2018; BYUNN, Eric; DAVIS Tom. The Bank of Google or Amazon? Don't count on it. American Banker, 15 de setembro de 2017.
} 
debate, via persuasão, apenas os problemas que 0 ator que exerce o poder considera importantes. $O$ ator que é alvo do exercício de poder pode saber ou não do poder do ator com quem interage, porém, independentemente disso, fornece o consentimento para legitimar as questões postas em debate. Ou seja, aceita, via persuasão, este enquadramento da agenda, que limita suas escolhas e pode modificar suas preferências iniciais. "In other words, it may be possible to shape others' preferences by affecting their expectations of what is legitimate or feasible. Agenda-framing focuses on the ability to keep issues off the table" (NYE, 2011, n.p).

A terceira face do poder, chamada de establishing preferences, é a capacidade de estabelecer as preferências iniciais do outro via ideias e crenças que façam com que o outro deseje o seu resultado como o dele. Esta terceira face do poder, como a segunda, ocorre exclusivamente pela persuasão, porém se diferencia das demais faces por se circunscrever à formação das preferências e não à modificação de preferências iniciais já estabelecidas. O exercício do poder é visto através da determinação das próprias necessidades iniciais do outro. Como o ator que exerce o poder teve papel fundamental na criação e configuração das crenças, percepções e preferências básicas, é improvável que o ator alvo esteja ciente ou perceba o efeito do poder a que está submetido. Segundo Nye (2011, n.p) "I can also exercise power over you by determining your very wants. I can shape your basic or initial preferences, not merely change the situation in a way that makes you change your strategy for achieving your preferences."

Acima fizemos algumas considerações sobre o caráter relacional do poder. Agora cabe indicar alguns pontos sobre o outro aspecto: os recursos de poder. Desprender os recursos de poder do caráter relacional apresenta certa controvérsia. Parte da literatura acadêmica não recomenda este tratamento. David Baldwin (2016, p.53) afirma que

The concept of a power resource is a relational concept in the sense that it has little or no meaning except within the context of a particular situation specified (at least) as to scope and domain. [...] The fact that power bases are multiple, nonhierarchical, and relational has many implications for power analysis.

Nós concordamos com a afirmação de Baldwin (2016). Um recurso de poder somente ganha importância se levarmos em conta o contexto particular em questão 
(escopo e domínio); que as bases do poder são múltiplas e variam de cultura para cultura; e que não há uma permanente hierarquia entre os recursos de poder. No fundo, mais do que os recursos que um ator tem a disposição para o exercício do poder, o que de fato importa é a habilidade que este ator tem para utilizar os recursos disponíveis em um determinado contexto com vista a atingir seus objetivos (NYE, 2011).

Ao desprender os recursos de poder, não desconsideramos seu caráter relacional, mas fazemos isso para melhor compreender como estes recursos emergem no espaço cibernético e com quem estão alocados em um contexto marcado por uma transição e difusão do poder (NYE, 2011). Isso se torna um artifício interessante, especialmente, se observarmos que a fonte cibernética de poder tem poucas limitações de domínio e de geografia.

O poder cibernético, como afirma Myriam Cavelty (2018), apresenta uma dificuldade de conceituação devido à baixa produção acadêmica sistemática, à forte influência de uma produção orientada para subsidiar a ação estatal e ao grande domínio que as questões militares dos Estados Unidos exercem sobre o direcionamento dos estudos. A autora também aponta uma baixa reflexão sobre as necessidades e funções do poder cibernético.

Ao tratar do poder cibernético, temos de ter o cuidado de, por um lado, não marginalizar os Estados, mas por outro lado, não podemos deixar de ressaltar a crescente influência que novas corporações tecnológicas, como Amazon, Google e Facebook, adquirem no ambiente da política internacional. Nesse sentido, Ávila e Pinheiro (2014, p.48) apontam que o

\footnotetext{
Poder informacional também é algo em si mesmo: é, por exemplo, a capacidade de se criar, usar, disseminar e controlar informação. É ainda uma relação de assimetria entre dois atores, onde um pode disponibilizar de mais elementos informacionais que os outros e, portanto, passar a dominá-lo.
}

Nye (2011) aponta que devido a sua grande mutação, o grande número de atores, a diminuição das barreiras de entrada e a oportunidade de ocultação, 0 ciberespaço difunde o poder entre uma gama mais diversificada de atores e reduz o diferencial de poder entre eles. Porém, "[...] relative reduction of power differentials is 
not the same as equalization. Large governments still have more resources." (NYE, 2011).

Nesta linha que destaca a capacidade estatal no ciberespaço, Lopes (2016, p.98) apresenta o conceito de Software Power, que consiste na "[...] capacidade político-estratégica de que dispõem Estados para intervir na política internacional ou externa de outro Estado via utilização de software". O autor procura destacar com este conceito a capacidade que alguns Estados possuem, via atuação no ciberespaço, de influenciar a política interna de outros Estados. Um exemplo disso foram as sanções dos Estados Unidos à Rússia, em 2016, em que as agências de inteligência dos EUA concluíram que os russos invadiram os servidores de e-mail do Partido Democrata e vazaram documentos por intermédio do Wikileaks. Isso teria afetado a disputa presidencial entre Hillary Clinton e Donald Trump em favor deste último ${ }^{21}$.

Um aspecto comum às distintas definições de poder cibernético é identificálo como a capacidade de utilizar os recursos do espaço cibernético para atingir objetivos políticos dentro e fora do ciberespaço. É uma fonte de poder que

can be defined in terms of a set of resources that relate to the creation, control, and communication of electronic and computerbased information-infrastructure, networks, software, human skills. This includes not only the Internet of networked computers, but also Intranets, cellular technologies, and space-based communications. (NYE, 2011, n.p).

\section{Os recursos de poder cibernético}

A partir do que já foi dito acima entendemos que é importante compreender melhor os tipos de recursos de poder que as novas tecnologias digitais possibilitam em um mundo interconectado. É possível identificar seis tipos principais de recursos de poder que se relacionam entre si e são distribuídos de forma desigual entre os diversos atores internacionais.

\footnotetext{
${ }^{21}$ How Russia Pulled off the Biggest Election Hack in U.S. History. Esquire, 20 out. 2016.. Disponível em: <https://www.esquire.com/news-politics/a49791/russian-dnc-emails-hacked/>. Acesso em: 11 de junho de 2018.
} 
O primeiro é o conhecimento especializado que se relaciona às tecnologias digitais. Pode ser o conhecimento que permite um indivíduo ou grupo ser capaz de se posicionar nas redes de comunicação globais a ponto de difundir seus interesses e valores, como o caso de Julian Assange e a criação do Wikileaks, ou até mesmo o conhecimento necessário para criar inovações tecnológicas que podem ter enorme repercussão mundial, a exemplo da criação da ferramenta de buscas Google por Larry Page e Sergey Brin ainda na segunda metade dos anos 1990. É importante lembrar que não se trata apenas das habilidades em manipular as tecnologias digitais existentes ou de desenvolver grandes empreendimentos a partir da criação de softwares, mas também de desenvolver os hardwares que estão envolvidos direta ou indiretamente no ciberespaço, como processadores, dispositivos móveis, sensores, entre outros.

O segundo recurso são os dados digitais que podem ser processados a fim de se obter informações úteis como hábitos de consumo, frequência de chuvas ou índices econômicos. Assim, há um enorme esforço para converter o máximo possível de dados analógicos em digitais, que vão desde acervos de bibliotecas até a superfície da terra ou a topografia dos oceanos. O acúmulo de dados é uma dimensão importante deste recurso, pois quando combinado com tecnologias e conhecimentos apropriados, pode transformá-los em informações relevantes a ponto de garantir um grande diferencial de poder de um ator em relação a outro.

A infraestrutura informacional, também chamada de ciberinfraestrutura (STAR; RUHLEDER, 1996), é o terceiro recurso de poder que deve ser considerado, já que os dados devem trafegar em quantidade e velocidade suficientes para que as redes possam se estabelecer, desenvolver e expandir, demandando instalações crescentes de estruturas de telefonia fixa e móvel até a instalação de cabos de fibra ótica interoceânicos ou o uso de satélites de comunicação. Além da questão do trânsito de dados, também há a questão da forma como os dados transitam e os padrões estabelecidos para essa finalidade, envolvendo questões que não se limitam às características técnicas e ao desenvolvimento de novas tecnologias e protocolos de comunicação, mas incluindo interesses estratégicos de Estados e grandes corporações, como pode ser notado nas discussões nacionais para adoção 
de um determinado padrão de televisão em alta-definição ou as questões envolvendo a construção de uma governança multissetorial da Internet. Cabe destacar, ainda, a crescente presença de empresas até então provedoras de conteúdo, como a Google e o Facebook, que agora investem em infraestrutura informacional, especialmente em cabos submarinos. Em três anos, a Google investiu US $\$ 30$ bilhões em cabos e continua expandindo ${ }^{22}$. Já o Facebook procura alternativas para levar Internet onde ainda não há conexão, como o drone Aquila, que conectaria até 4 bilhões de pessoas ${ }^{23}$.

A capacidade computacional é outro recurso de poder muito importante, pois quanto maior a velocidade e capacidade de processamento e armazenamento de dados maior são as possibilidades de utilização dos seus resultados. Investimentos constantes são realizados no desenvolvimento de novos hardwares, assim como novas arquiteturas de processamento, tendo repercussão importante em todos os aspectos da vida interconectada. Sua concentração permite ao detentor deste recurso obter grandes vantagens competitivas em diversos setores, como pode ser observado nos supercomputadores para cálculos e simulações científicas e militares, na corrida para o desenvolvimento da computação quântica, ou no enorme poder de processamento feito de forma distribuída da rede Bitcoin.

O que chamamos de base de usuários, ou seja, as redes de indivíduos ou grupos interconectados, também pode ser considerada como um recurso de poder. São as diversas redes que se criam em plataformas de interação virtual como o Facebook ou Twitter, as comunidades envolvidas em projetos de software livre e de código aberto, os usuários de dispositivos móveis como o Android, usuários de sistemas operacionais como Microsoft, Apple e as diversas distribuições Linux, ou

\footnotetext{
${ }^{22}$ Esse tipo de investimento da Google busca não apenas expandir conexões mundo afora, como também prover uma conexão mais rápida e confiável, capaz de levar todos os serviços da empresa em alta qualidade para os seus clientes. Expanding our global infrastructure with new regions and subsea cables. Google blog, 16 jan 2018. Disponível em: <https://blog.google/topics/googlecloud/expanding-our-global-infrastructure-new-regions-and-subsea-cables/>. Acesso em 7 mar 2018.

23 O Facebook vem investindo fortemente na ideia de conectar a parcela do mundo ainda desconectada. Além do serviço Internet.org, que fornece acesso gratuito à alguns aplicativos como a própria rede social, a empresa também arrisca levar conexão através de drones, como é o caso do Aquila. Facebook drone that could bring global internet access completes test flight. The Guardian, 2 jul 2017. Disponível em: <https://www.theguardian.com/technology/2017/jul/02/facebook-drone-aquilainternet-test-flight-arizona>. Acesso em 7 mar 2018.
} 
até mesmo as redes envolvidas no desenvolvimento e uso de criptomoedas. Essas bases de usuários são formadas na medida em que as novas tecnologias surgem e se apresentam como ferramentas que podem atender necessidades e interesses de indivíduos, grupos, empresas, governos, universidades e outros. São, em sua essência, redes de interdependência entre os mais variados tipos de atores. Sua importância não se fundamenta somente no tamanho, densidade e alcance que estas redes podem atingir, mas também como fonte contínua de produção de dados digitais que podem revelar padrões de interação social, comportamento econômico, expectativas políticas, enfim, informações que podem ter usos múltiplos, desde o atendimento de interesses comerciais até a construção de estratégias de resistência política de atores de menor poder relativo. É a partir destas bases de usuários que o processo de digitalização da vida social se expande e se aprofunda.

Por fim, o último recurso de poder, e que é o principal foco deste texto, são os algoritmos. Em termos de ciência da computação, algoritmos são basicamente uma descrição de procedimentos computacionais (SEAVER, 2017), instruções para que uma máquina resolva um problema (INTRONA, 2013) a partir de regras e lógicas que se aplicam aos dados. Mas Paul Dourish (2016) nota que a definição do termo pode variar historicamente, a depender também de pessoas e situações sociais. Por exemplo, a definição seria diferente entre um matemático da década de 1940 e um cientista de dados que trabalha na Google em 2018.

São os algoritmos que dão utilidade aos dados, viabilizam a automação, tomam decisões, permitem o processo de comunicação no ciberespaço entre humanos ou entre máquinas, assim como torna possível a inteligência artificial. Pode-se tratar de um algoritmo dedicado a realizar uma tarefa específica e repetitiva em uma indústria automotiva, controlando robôs a partir de dados previamente fornecidos, ou algoritmos de aprendizado de máquina que reconhecem padrões de consumo coletivo e preferências individuais a fim de sugerir um portfólio de produtos ou serviços especializado para cada consumidor, a fim de manter o cliente satisfeito e maximizar os lucros, otimizando os recursos de empresas como Netflix, Amazon ou eBay. 
Não temos a intenção de detalhar os diversos tipos de algoritmos existentes, mas os concentrar em duas categorias fundamentais: os algoritmos que não aprendem e os que aprendem, aqui chamados de inteligentes. O primeiro é predominantemente focado na solução de problemas detalhadamente conhecidos, realizando uma sequência de atividades pré-programadas por seres humanos a fim de obter um resultado específico, ou seja, a máquina executa de forma exata a sequência de procedimentos e decisões estabelecidas na programação, sem variações ou ajustes automáticos.

Já o algoritmo inteligente tem origem em uma programação humana, mas tem a capacidade de reconhecer alterações no padrão esperado de problemas e ações, aprendendo com essas alterações e podendo ajustar seu próprio parâmetro de funcionamento de forma automática para continuar apresentando resultados sem, necessariamente, a intervenção humana. Tanto um como o outro coleta, organiza e processa dados a fim de gerar informações, mas o que em última instância os diferencia é a enorme ampliação da capacidade de adaptação que os algoritmos inteligentes propiciam aos seus detentores dentro de um ciberespaço cada vez mais complexo.

\section{As Transnacionais de Tecnologia e o Poder dos Algoritmos}

Temos hoje transnacionais das tecnologias da informação e comunicação que concentram grande parte dos recursos de poder cibernético, como dados, poder computacional, inovação e controle sobre algoritmos que permitem ampliar e manter grandes bases de usuários, que por si só geram continuamente uma imensa quantidade de informações. Essas informações permitem um conhecimento de padrões de comportamento e de consumo, essenciais não apenas para o comércio como também para o próprio Estado, na tentativa de exercer algum controle sobre determinada população. Como colocam Ávila e Pinheiro (2014, p.15) "o domínio da informação é elemento base da construção do poder na contemporaneidade". Essa enorme quantidade de dados é facilmente coletada a partir dos vários dispositivos a que a sociedade está submetida na maior parte do tempo como dispositivos móveis, 
telefonia fixa, televisão por cabo e satélite, computadores, consoles de videogames, entre outros.

O uso constante dessas ferramentas acaba por gerar uma quantidade cada vez maior de dados, sejam mensagens instantâneas, fotos, vídeos, notícias, serviços de localização, transações financeiras, entre muitos outros. São dados que se referem, em sua maioria, a questões cotidianas e sociais, que facilmente influenciam os mercados e o consumo, presentes desde os primeiros anos da web. Yochai Benkler (2006) chama a atenção para os elementos de informação e conhecimento, que têm um papel relevante na oportunidade econômica, na criação de riqueza e no desenvolvimento humano. Desse modo, os dados permitem conhecer o comportamento dos indivíduos e torna-se um ativo de poder das companhias que obtêm e concentram essas informações. Ao mesmo tempo em que os usuários exercem certa liberdade online, com grandes capacidades de expressão, criação e autonomia, acabam também por entregar toda essa gama de informação às poucas empresas que exercem domínio sobre o fluxo de dados de grandes bases de usuários. Processo semelhante ao que Castells (2011) identificou como a maneira pela qual a liberdade é transformada em commodity através dos serviços de computação em nuvem.

Assim, os diversos setores econômicos passam por profundas transformações graças ao conhecimento das preferências dos consumidores, cada vez mais precisos sobre suas escolhas, opções de entretenimento, viagens, todos coletados através dos dados que eles próprios disponibilizam, na maioria das vezes sem consciência de como essas informações serão utilizadas. Como já exposto anteriormente, pode-se relacionar essa prática com o conceito co-optive power (Nye, 2011), no qual um ator formula as necessidades básicas do outro. Com o acesso e análise do comportamento coletivo e individual destas grandes bases de usuários a empresa que as domina pode induzir necessidades sem que os usuários percebam o exercício de poder.

Atualmente, há um cenário dominado por grandes corporações que atuam globalmente na Internet, como Apple, Amazon, Google, Facebook e Microsoft, que são responsáveis pela gigante concentração dos dados e informações de grande 
parte da população mundial ${ }^{24}$. A Google domina pouco mais de $80 \%$ das ferramentas de busca mundialmente ${ }^{25}$, obtendo lucro através de anúncios publicitários. A empresa vale cerca de US $\$ 100$ bilhões, sendo a segunda marca mais valiosa do mundo ${ }^{26}$, atrás apenas da Apple. Já o Facebook possui cerca de 2 bilhões de usuários ativos mensalmente ${ }^{27}$. Outro dado interessante é o fato de que muitos usuários da rede social a consideram como "a Internet" ou "a web", evidenciando que o uso da Internet se faz por completo apenas pela plataforma. ${ }^{28}$

Apesar da grande expansão no uso e acesso à Internet, ainda persistem importantes limitadores, havendo uma grande parcela da população mundial que se encontra excluída ou que tem uma inclusão muito limitada. Dos 7 bilhões de pessoas no planeta, 4 bilhões têm acesso à Internet, dentre as quais cerca de 3 bilhões estão em redes sociais ${ }^{29}$. No Brasil, $67 \%$ das pessoas que estão conectadas utilizam apenas o smartphone, enquanto que $44 \%$ acessam principalmente pelos computadores ${ }^{30}$.

O acesso cada vez mais fácil e menos custoso à população possibilita uma série de liberdades e conquistas de novos conhecimentos, tanto para quem fornece o serviço quanto para o próprio usuário. Detendo essa gama de informações que se transformam em conhecimento, que influenciam ideias e modificam padrões

\footnotetext{
${ }^{24}$ Não se desconsidera, além dessas, a situação específica da China, cujo mercado de tecnologia começa uma expansão para o Ocidente, caso de empresas como Didi Chuxing, Alibaba Group e Baidu. A China possui uma internet altamente censurada pelo governo e exige condições para permitir que empresas ocidentais como o Facebook atuem no país.
}

${ }^{25}$ Desktop Search Engine Market Share. Net Market Share, dez 2014. Disponível em: $<$ https://goo.gl/naqnh2>. Acesso em 2 ago 2017.

${ }^{26}$ The World's Most Valuable Brands - 2017 RANKING. Forbes, maio 2017. Disponível em: $<$ https://www.forbes.com/companies/google/>. Acesso em 2 ago 2017.

${ }^{27}$ Facebook Stats. Newsroom.fb, jun 2017. Disponível em: <https://newsroom.fb.com/company-info/>. Acesso em 2 ago 2017.

${ }^{28} 55 \%$ dos brasileiros entrevistados por uma pesquisa da publicação Quartz afirmaram que "o Facebook é a Internet". Fonte: Millions of Facebook users have no idea they're using the internet. Quartz, fev 2015. Disponível em: <https://goo.gl/10QKNV>. Acesso em 2 ago 2017.

${ }^{29}$ Digital in 2018: World's Internet Users Pass the 4 billion Mark. We Are Social, 30 jan 2018. Disponível em: <https://wearesocial.com/blog/2018/01/global-digital-report-2018>. Acesso em 12 mar 2018.

${ }^{30}$ Levantamento realizado pelo Google's Consumer Barometer em 12 de março de 2018. Disponível em: <https://goo.gl/a8xLuY>. Acesso em 12 de março de 2018. 
culturais, as empresas se beneficiam do que Benkler (2008) denomina "produção social". As ideias que circulam online são produto de uma ação coletiva, podendo ser concentradas graças à própria estrutura da Internet. Há, então, acúmulo de recursos de poder cibernético e econômico em algumas corporações que criam camadas de interação muito fortes e que se apropriam dessa produção social, aumentando cada vez mais sua influência sobre as bases de usuários. É o que acontece cotidianamente ao fazer uma busca no Google, ou postar, compartilhar e curtir conteúdo em redes sociais como o Facebook.

Estas empresas são centrais no ciberespaço e apresentam forte concentração dos recursos de poder cibernético indicados anteriormente. A concentração desses recursos, por sua vez, faz com que a capacidade de atrair recursos financeiros aumente exponencialmente ${ }^{31}$, possibilitando aquisições de novas tecnologias digitais e plataformas que poderiam ser uma concorrência futura, mas que logo são absorvidas por essas grandes corporações, agregando ainda mais dados e ampliando suas bases de usuários. São exemplos a compra do YouTube pela Google, em 2006 (apenas 1 ano após o domínio ter sido registrado) e a compra do Instagram pelo Facebook em 2011.

Essas grandes transnacionais dominam diversos serviços online e oferecem comunicação rápida e a baixo custo para uma grande parcela da população, ganhando cada vez mais capacidade de influenciar comportamentos e jurisdições nacionais. A Google é mais uma vez um bom exemplo: a partir do conhecimento para desenvolver a inovação tecnológica, representada pelos algoritmos de indexação e busca do conteúdo existente na Internet, não só tornou a rede mundial de computadores mais fácil de ser utilizada mas também acumulou uma enorme base de usuários, evoluiu para algoritmos inteligentes combinados com um crescente poder computacional, e tornou-se provedora de diversos serviços em nuvem (e-mail, armazenamento de dados, localização, compartilhamento de vídeos e fotos, sistemas operacionais de dispositivos móveis, infraestrutura de virtualização, e outros) prestados "gratuitamente" ou de forma remunerada.

${ }^{31}$ These six tech companies are worth $\$ 500$ billion, and their earnings are about to sway the market. Market Watch, 31 de janeiro de 2018. Disponível em: <https://archive.is/5eO9h>. Acesso em 12 de março de 2018. 
Ao mesmo tempo em que empresas como a Google, Facebook, Netflix e Amazon, facilitam o acesso às informações, entretenimento e ferramentas digitais úteis no cotidiano das pessoas e organizações, estas também concentram recursos de poder cibernético e econômico, aumentando progressivamente sua capacidade de influência política. Pode ser uma explicação para uma medida tomada recentemente pelo governo estadunidense: a revogação da neutralidade da rede.

Tal princípio preza para que não haja discriminação de conteúdo por parte dos provedores de acesso à Internet. Basicamente, foi como a rede sempre funcionou: provedores de acesso não podem bloquear, acelerar ou diminuir a velocidade de certas aplicações e websites. $O$ órgão regulador das telecomunicações nos Estados Unidos, o Federal Communications Commission (FCC), revogou esse princípio no fim de 2017 para permitir que empresas que dominam parte dos recursos de infraestrutura informacional como a Verizon e a Comcast (dois dos maiores provedores de conexão do país) controlassem a disponibilidade e acessibilidade de algumas aplicações (como o Facebook ou Whatsapp), o que resultaria em maiores lucros, já que as empresas poderiam cobrar mais para certa aplicação ter maior velocidade, por exemplo. Para além do aspecto financeiro, a questão da neutralidade da rede atinge diretamente importantes questões políticas, já que permite a liberdade de expressão e livre disseminação de conteúdo na rede, permitindo a todos os usuários terem acesso a qualquer informação online. O não cumprimento dessa neutralidade pode ser entendido como censura ou favorecimento econômico a grandes corporações de tecnologia.

O caso Snowden também ajuda a compreender as relações entre Estado, sociedade e poder cibernético. Em 2013, Edward Snowden, então analista da Agência de Segurança Nacional dos Estados Unidos (NSA), revelou como seu país espionava seus cidadãos e os de outros países, incluindo chefes de Estado, através da Internet e de escutas telefônicas. Naquele momento este indivíduo até então desconhecido transforma-se rapidamente em um ator internacional em virtude do seu conhecimento sobre o funcionamento das tecnologias digitais que operava e de sua situação privilegiada em relação ao acesso aos dados e informações sigilosas. O caso é diretamente ligado às empresas como Google e Facebook, já que um dos 
programas de vigilância eletrônica, o $\mathrm{PRISM}^{32}$, tinha acesso direto aos servidores dessas companhias ${ }^{33}$. O Estado norte-americano, detendo recursos como conhecimento, algoritmos, poder computacional e infraestrutura informacional, lançou-se sobre dois deles que estavam fortemente concentrados nas duas transnacionais de tecnologia, os dados e as bases de usuários. Não ficou claro se essas empresas cooperaram com o Estado ou também foram vítimas dessa interceptação de dados, mas o fato é que esse tipo de coleta realizada por algoritmos também pode favorecer governos, a fim de conhecer melhor seus cidadãos, controlar e influenciar comportamentos, independente do nível de abertura política dos países.

Hoje é fácil perceber a noção que se tem de algoritmo devido às várias plataformas que acessamos diariamente. Basta ver na Netflix que o catálogo exposto é diferente para cada assinante, pois seu algoritmo de recomendação é personalizado. É o que alguns autores denominam de "cultura algorítmica": o uso de processos computacionais para classificar, hierarquizar pessoas, objetos, ideias e lugares, além de hábitos de conduta, pensamentos e expressões que surgem durante o processo (STRIPHAS, 2012). Toda essa coleta de informações se torna cada vez mais útil e precisa graças aos algoritmos presentes nas plataformas digitais que utilizamos, como o Facebook ou o Instagram. Eles selecionam e organizam as informações, no caso das redes sociais, para criar, por exemplo, a timeline (feed de postagens) e todo o conteúdo que cada usuário verá. $\mathrm{O}$ ambiente virtual é, portanto, personalizado exclusivamente para cada usuário, com base nos seus gostos, nos seus likes (curtidas), nas suas atividades registradas (ver um filme, participar de um evento, etc.). Não podemos esquecer que os algoritmos estão em muitas outras plataformas que utilizamos diariamente, além das já citadas. A hiperconectividade gerou uma dependência de novos serviços que surgem e

\footnotetext{
${ }^{32}$ PRISM é um dos programas da NSA revelados por Snowden, através do qual a vigilância massiva permite acesso à dados de navegação na Internet, inclusive conteúdos de e-mails, chamadas de voz e vídeo, transferência de arquivos, entre outros. Empresas como Google, Apple, Facebook e Skype apareceram nos arquivos mostrados por Snowden como "colaboradores" do projeto.

${ }^{33}$ NSA Prism program taps in to user data of Apple, Google and others. The Guardian, 7 jun 2013. Disponível em: <https://goo.gl/wXD7jL>. Acesso em 7 fev 2017.
} 
crescem exponencialmente. É o caso dos serviços como o Uber ou Airbnb, onde há grande coleta de dados e avaliações de preferências dos consumidores.

Os algoritmos de aprendizado de máquina evoluem a partir do reconhecimento de cada comportamento e de modelos usados para treiná-los. No caso de plataformas como o Facebook e YouTube, esses modelos são extraídos das informações provenientes das interações nas bases de usuários. Assim, quanto mais se usa, mais informação o modelo terá sobre o usuário e "melhor" serão as recomendações. Como consequência, o usuário poderá receber informações úteis e que provavelmente estejam compatíveis com seu perfil de comportamento, mas por outro lado, também pode ficar mais restrito à média desse comportamento, pois 0 usuário tenderá a concentrar-se cada vez mais nas sugestões correspondentes com seu perfil e suas ideias, ou seja, os algoritmos vão tendo cada vez mais influência na formação do comportamento do usuário ao limitar e selecionar os conteúdos que podem mais facilmente ser acessados. Assim, os processos de socialização vão sendo influenciados cada vez mais pela presença dos algoritmos na vida cotidiana.

Diante dessa tendência, parece normal que se questione quem tem controle sobre esses processos e como esses algoritmos são construídos e para qual finalidade. Questionar e conhecer o funcionamento dos algoritmos, assim como eles se disseminam, é muito importante nos dias atuais, embora alguns setores sejam contrários a divulgar esse tipo de informação, pois os algoritmos em si seriam um tipo de segredo industrial.

\section{Considerações finais: as relações internacionais na era digital}

A atual fase das relações internacionais é singular não somente devido às mudanças sistêmicas, provocadas pelo processo de transformação na distribuição do poder mundial e também como efeito da crise econômica internacional de 2008, mas principalmente pela aceleração e expansão da interconectividade no interior das sociedades e entre sociedades diferentes. Elas são combinadas com um conjunto de novas tecnologias digitais que tendem à universalização e que 
intensificam, simultaneamente, importantes mudanças no padrão de interação social e, portanto, alterando a forma como as relações de poder são estabelecidas.

Os últimos anos estão sendo marcados tanto pelo crescimento do número de atores com capacidade real de influência nas relações internacionais, quanto pelo aumento de episódios que revelam crises e instabilidade política nos Estados nacionais, na diplomacia e nas instituições internacionais. Fatos como as revelações de informações sigilosas pelo Wikileaks, o processo eleitoral norte-americano que resultou na vitória de Donald Trump, o plebiscito britânico que decidiu pelo Brexit ou as manifestações de rua em junho de 2013 no Brasil, são exemplos importantes de como a política nacional e internacional tem se modificado.

No caso das instituições internacionais que são criadas, desenvolvidas e legitimadas a partir de determinados padrões de comunicação estabelecidos socialmente, verifica-se que o processo contínuo de construção e reconstrução institucional é abalado na medida em que as novas tecnologias digitais modificam a capacidade dos atores envolvidos e a maneira como as interações são realizadas. Para que as instituições possam prosperar é necessário manter uma adequada capacidade de adaptação ao ambiente em que atuam. O problema está no fato de que em geral as mudanças institucionais são lentas, entrando em contradição com a enorme velocidade com que as inovações tecnológicas impactam os processos de aceitação e legitimação por parte dos seus membros. Como resultado, tem-se a propagação das crises de expectativa, dificultando justamente 0 trabalho fundamental das instituições: criar estabilidade e um ambiente de confiança para que seus objetivos e dos seus membros sejam atingidos.

Ao tratar das relações internacionais e o ciberespaço, Choucri (2014) entende que o modelo westphaliano de sistema internacional é influenciado pelas transformações provenientes das capacidades cibernéticas dos atores internacionais, sendo uma ameaça potencial à segurança nacional e à ordem internacional tal como a conhecemos. A expansão do acesso cibernético, nesta concepção, é vista como uma das principais fontes de distúrbio. Assim, o entendimento tradicional sobre as relações internacionais contemporâneas é desafiado por algumas das principais características do ciberespaço: a substituição 
da temporalidade convencional pela instantaneidade, a relativização das barreiras geográficas e físicas, a permeabilidade das fronteiras e jurisdições, a fluidez com que mudanças e reconfigurações se processam, a redução das barreiras de participação promovendo maior possibilidade de expressão e ativismo político, a questão da atribuição no que diz respeito ao obscurecimento das identidades dos atores e das ações realizadas e, por fim, as possibilidades de ignorar mecanismos de responsabilização.

No parágrafo anterior vemos que a autora apresenta dois aspectos importantes para compreensão de como as relações internacionais são afetadas pelas mudanças provocadas pelas novas tecnologias digitais. $O$ primeiro é $O$ entendimento genérico do que sejam as capacidades cibernéticas dos atores internacionais. A dificuldade em compreender a composição e o funcionamento destas novas capacidades não é exclusiva de Choucri (2014). Autores como Cavelty (2018) e Kuehl (2009) também apontam para esta dificuldade. Isso demonstra a necessidade de se conhecer melhor os recursos de poder na era digital. Comparar capacidades dos principais atores internacionais é uma das formas mais comuns de buscar compreender o diferencial de poder existente e como isso pode alterar o ordenamento político mundial. Fazer essa comparação nos dias atuais vem se tornando, portanto, cada vez mais difícil na medida em que ocorre um processo de aceleração e proliferação de inovações tecnológicas que mudam comportamentos sociais e as referências que organizam as expectativas nas relações internacionais. Além disso, essas inovações podem suplantar rapidamente capacidades tradicionais dos principais atores internacionais.

Um forte exemplo é o crescimento de empresas focadas no desenvolvimento de tecnologias consideradas sensíveis, antes mais dependentes das estruturas e decisões de atores estatais, ganhando importância e evidência através do conhecimento de como se beneficiar das redes de comunicação atuais para não só ampliar seus interesses econômicos, mas também difundir seus valores sobre o papel que as novas tecnologias e os atores privados podem ter. É o caso da Blue Origin criada em 2000 por Jeff Bezos (fundador da Amazon) e, principalmente, a SpaceX, fundada em 2002 por Elon Musk, que tem desenvolvido inovações importantes no campo aeroespacial, principalmente com o sistema de lançamento 
de foguetes que retornam à Terra e podem ser reaproveitados, reduzindo drasticamente os custos deste tipo de operação. O lançamento do foguete Falcon Heavy, em fevereiro de 2018, atraiu atenção mundial ao colocar um Tesla Roadster (um carro elétrico da empresa Tesla, também de Musk) em órbita. Com as imagens transmitidas mundialmente, o empresário não apenas empreendeu uma impactante ação de marketing, mas também apresentou uma alternativa competitiva aos seus concorrentes internacionais. Tal iniciativa tende a respaldar as pretensões da SpaceX perante ao governo dos EUA, seu principal cliente.

Já o segundo aspecto trata das características intrínsecas do ciberespaço mencionadas acima. Estas apontam não só para as alterações ocorridas no âmbito das práticas políticas, mas também para as mudanças de perspectiva a respeito das principais referências que orientam os comportamentos dos atores, os processos de socialização internacional, assim como o funcionamento das principais instituições internacionais.

Se olharmos para a questão da permeabilidade das fronteiras e jurisdições, apenas para exemplificar, veremos que esta situação vem se intensificando desde os anos 1970. No entanto, nos últimos anos é possível identificar grandes transformações em diferentes esferas de interação social e nas práticas políticas como resultado das inovações no campo das tecnologias de informação e comunicação. Sem desmerecer as causas econômicas e sociais de fenômenos recentes, fica muito difícil nos dias de hoje tentar compreender diversos acontecimentos políticos sem considerar o papel destas novas tecnologias de comunicação e o uso dos recursos de poder digitais, já tratados neste artigo. A amplitude desta nova situação não se restringe ao ciberterrorismo ou ao ciberativismo, que se concentram fundamentalmente nesta classe de recursos de poder, como infraestrutura de comunicações ou dados, sendo possível afirmar que todos os processos políticos, nacionais ou internacionais, em maior ou menor intensidade, ganham uma dimensão cibernética que não pode ser ignorada. $O$ crescimento da intolerância política e da xenofobia em vários países, ou a interferência das redes sociais digitais nos processos eleitorais, são exemplificações desta nova realidade. 


\section{Referências}

ÁVILA Rafael. Oliveira de.; PINHEIRO Marta Kerr. Poder Informacional nas Relações Internacionais Contemporâneas. Monções: Revista de Relações Internacionais da UFGD, Dourados, v.3. n.5, jan./jun., 2014.

BALDWIN, David. Power and International Relations: A Conceptual Approach. Princeton/Oxford: Princeton University Press, 2016.

BARNETT Michael; DUVALL, Raymont. Power in Global Governance. New York: Cambridge University Press, 2005.

BERENSKOETTER Felix.; WILLIAMS, Michael. Power in World Politics. New York: Routledge, 2007.

BENEDIKT, Michael. Cyberspace: Some Proposals, IN: BENEDIKT, Michael (org.) Cyberspace: First Steps. Cambridge MA: The MIT Press. 1994.

BENKLER, Yochai. Open-source economics. TED Talks, 2008. Disponível em: $<$ https://goo.gl/cRTXCT>. Acesso em 30 nov 2017.

BENKLER, Yochai. The Wealth of Networks: How Social Production Transforms Markets and Freedom. Yale University Press, New Haven and London, 2006.

CANABARRO, Diego Rafael. Governança global da Internet: tecnologia, poder e desenvolvimento. Tese de Doutorado em Ciência Política, Universidade Federal do Rio Grande do Sul, 2014.

CASTELLS, Manuel. A Network Theory of Power. International Journal of Communication, 2011. Disponível em: $<$ https://faculty.georgetown.edu/irvinem/theory/Castells-Network-Power-2011.pdf>. Acesso em 5 mar 2018.

CAVELTY, Myriam. Europe's cyber-power. European Politics and Society, 2018. Disponível em: <https://www.tandfonline.com/doi/abs/10.1080/23745118.2018.1430718>. Acesso em 5 mar 2018.

CHOUCRI, Nazli. Cyberpolitics in International Relations. MIT Press, 2012.

CHOUCRI, Nazli. Co-Evolution of Cyberspace and International Relations: New Challenges for the Social Sciences. Massachusetts Institute of Technology Political Science Department, Research Paper No. 2014-29. 2014. Disponível em: $<$ https://papers.ssrn.com/sol3/papers.cfm?abstract id=2514532>. Acesso em 26 fev 2018.

DODGE, Martin.; KITCHIN, Rob. Mapping Cyberspace. Taylor \& Francis e-Library. 2001. 
DOURISH Paul. Algorithms and their others: Algorithmic culture in context. Big Data \& Society, $2016 . \quad$ Disponível em: $<$ http://journals.sagepub.com/doi/pdf/10.1177/2053951716665128>. Acesso em 28 fev 2018.

FINNEMORE, Martha; GOLDSTEIN, Judith. Back to Basics: State Power in a Contemporary World. New York: Oxford University Press, 2013.

GUZZINI, Stefano. Power, realism and constructivism. New York/London: Routledge, 2013.

INTRONA, Lucas. Algorithms, Governance and Governmentality: On governing academic writing. Science, Technology, \& Human Values, Vol 41, Issue 1, pp. 17 49. 2015.

Disponível

em: <http://journals.sagepub.com/doi/abs/10.1177/0162243915587360\#articleCitationDo wnloadContainer>. Acesso em 28 fev 2018.

KRASNER, Stephen. Causas Estruturais e Consequências dos Regimes Internacionais: regimes como variáveis intervenientes. Revista de Sociologia e Política, Curitiba, v. 20, n. 42, p. 93-110, jun. 2012. p. 94.

KUEHL, Daniel. From Cyberspace to Cyberpower: Defining the Problem. In: KRAMER Franklin; STARR, Stuart; WENTZ, Larry (Org.). Cyberpower and National Security. Potomac Books, University of Nebraska Press. 2009. Disponível em: <http://www.jstor.org/stable/j.ctt1djmhj1.7>. Acesso em 7 mar 2018.

KURBALIJA, Jovan. An Introduction to Internet Governance. DiploFoundation, 2014. $6 a$ ed.

LEMOS, Ronaldo. Democracia está sob a mira de ciberataques. Folha de São Paulo, 8 maio 2017.

LOPES, Gills. Relações Internacionais Cibernéticas (CiberRI): Uma Defesa Acadêmica a Partir dos Estudos de Segurança Internacional. Tese de Doutorado em Ciência Política, Universidade Federal de Pernambuco, 2016.

NYE, Joseph. The future of power. New York: PublicAffairs, 2011 (versão não paginada, obra em formato .mobi ).

NYE, Joseph. How Sharp Power Threatens Soft Power. Foreign Affairs, 24 jan 2018. Disponível em:<https://www.foreignaffairs.com/articles/china/2018-01-24/how-sharppower-threatens-soft-power>. Acesso em 27 fev 2018.

NYE, Joseph. Power in the Global Information Age: From Realism to Globalization. Taylor \& Francis e-Library, 2004.

PORTELA, Lucas. Agenda de Pesquisa sobre o Espaço Cibernético nas Relações Internacionais. Revista Brasileira de Estudos de Defesa. v. 3, № 1, jan./jun. 2016, p. 
91-113. Disponível em: <https://rbed.abedef.org/rbed/article/viewFile/62071/37922>. Acesso em 26 fev 2018.

SEAVER, Nick. Algorithms as culture: Some tactics for the ethnography of algorithmic systems. Big Data and Society, 2017. Disponível em: $<$ http://journals.sagepub.com/doi/pdf/10.1177/2053951717738104>. Acesso em 28 fev 2018.

STRIPHAS Ted. What is an Algorithm? Culture Digitally. 2012. Disponível em: <http://culturedigitally. org/2012/02/what-is-an-algorithm/>. Acesso em 28 fev 2018.

VENTRE, Daniel. Ciberguerra. In: XIX Curso Internacional de Defensa Jaca Seguridad global y potencias emergentes en un mundo multipolar. 2011. Disponível em:

$<$ https://publicaciones.defensa.gob.es/media/downloadable/files/links/P/D/PDF48.pdf >. Acesso em 26 fev 2018.

Recebido em 28/02/2018. Aprovado em 28/06/2018. 